\title{
Intra-islet Insulin Permits Glucose to Directly Suppress Pancreatic A Cell Function
}

\author{
C. J. Greenbaum, P. J. Havel, G. J. Taborsky, Jr., and L. J. Klaff \\ Veterans Medical Center and the Division of Metabolism, Endocrinology, and Nutrition, \\ Department of Medicine, University of Washington, Seattle, Washington 98108
}

\begin{abstract}
Inhibition of pancreatic glucagon secretion during hyperglycemia could be mediated by $(a)$ glucose, $(b)$ insulin, $(c)$ somatostatin, or $(d)$ glucose in conjunction with insulin. To determine the role of these factors in the mediation of glucagon suppression, we injected alloxan while clamping the arterial supply of the pancreatic splenic lobe of dogs, thus inducing insulin deficiency localized to the ventral lobe and avoiding hyperglycemia. Ventral lobe insulin, glucagon, and somatostatin outputs were then measured in response to a stepped IV glucose infusion. In control dogs glucagon suppression occurred at a glucose level of $150 \mathrm{mg} / \mathrm{dl}$ and somatostatin output increased at glucose $>250$ $\mathrm{mg} / \mathrm{dl}$. In alloxan-treated dogs glucagon output was not suppressed nor did somatostatin output increase. We concluded that insulin was required in the mediation of glucagon suppression and somatostatin stimulation. Subsequently, we infused insulin at high rates directly into the artery that supplied the beta cell-deficient lobe in six alloxan-treated dogs. Insulin infusion alone did not cause suppression of glucagon or stimulation of somatostatin; however, insulin repletion during glucose infusions did restore the ability of hyperglycemia to suppress glucagon and stimulate somatostatin. We conclude that intra-islet insulin permits glucose to suppress glucagon secretion and stimulate somatostatin during hyperglycemia. (J. Clin. Invest. 1991. 88:767-773.) Key words: insulin • glucagon • hyperglycemia)
\end{abstract}

\section{Introduction}

It has long been known that in healthy subjects glucagon secretion is suppressed by hyperglycemia; whereas, Type I diabetic patients have relatively elevated glucagon levels despite hyperglycemia. Hyperglucagonemia in turn perpetuates diabetic hyperglycemia because glucagon potently stimulates hepatic glucose output. This old observation of increased glucagon secretion in Type I diabetes has recently been bolstered by reports of increased levels of glucagon mRNA in the pancreas of diabetic rats suggesting increased glucagon synthesis as well as secretion (1).

The abnormal regulation of the A cell in Type I diabetes is presumably related to the insulin deficiency and resultant $a b-$ normal internal milieu of the diabetic islet. However, the exact

Address correspondence and reprint requests to Dr. Carla J. Greenbaum, Veterans Affairs Medical Center, Medical Services (111), 1660 South Columbian Way, Seattle, WA 98108.

Received for publication 5 February 1991 and in revised form 29 May 1991.

The Journal of Clinical Investigation, Inc.

Volume 88, September 1991, 767-773 mechanism responsible for this defect continues to be debated because of conflicting studies and inadequate understanding of the mechanisms of glucagon suppression by hyperglycemia in the nondiabetic islet. Previous experiments in man and experimental animals have suggested at least four possible mechanisms of A cell suppression during hyperglycemia. Thus, A cell suppression could be caused by: $(a)$ glucose per se $(2-5),(b)$ insulin (6-11), (c) pancreatic somatostatin (12), or $(d)$ an action of glucose to directly suppress glucagon secretion which is dependent on adequate islet insulin levels (13). Such a permissive effect of insulin has recently been demonstrated in adipose tissue in which insulin exposure is required to maintain the biosynthesis of a glucose transporter (14).

Advances in our understanding of both the microcirculation of the islet and the effects of chronic hyperglycemia on glucose recognition by islet cells emphasize some of the then unrecognized problems with the experimental design of earlier experiments. For example, although in vitro studies of isolated islets have had the advantage of strict control of the ambient glucose level, the question of whether these results are applicable to the in vivo situation has been raised by evidence of directional islet blood flow (see below) (15). Previous in vivo methods, which are usually more physiologic, also had disadvantages. For example, to assess the role of insulin, B cell cytotoxins have been given to the whole animal which necessarily creates a chronic hyperglycemia. Recent evidence suggests that chronic hyperglycemia itself can decrease the sensitivity of $B$ and A cells to acute glucose exposure (16-22). Therefore, the chronically diabetic animal may not be the best model in which to determine if the acute glucose exposure per se can directly suppress the A cell under physiologic conditions in the nondiabetic animal. Finally, studies on islet microvasculature suggest that the A cell is downstream from the B cell and therefore presumably bathed by high concentrations of insulin (15). Thus, very high rates of local insulin infusions may be needed to adequately replace the insulin lost by chemical destruction of the beta cell. In previous studies the amount of insulin required for repletion has probably been underestimated.

In light of these newly recognized concerns, we developed an animal model, adopted from that of Gomori and Goldner (23), in which chronic beta cell deficiency was present only in the ventral lobe of the canine pancreas. The functioning dorsal lobe continued to secrete sufficient insulin to maintain fasting normoglycemia in these animals. We were then able to study the effects of acute increases of glucose on glucagon secretion from the B cell-deficient lobe in chronically euglycemic animals. Subsequently, we infused insulin at high rates directly into the pancreatic artery which supplied the beta cell deficient lobe in order to normalize the intra-islet insulin levels. We were thus able to assess the effect of insulin alone or in combination with acute hyperglycemia on the A cell now reexposed to high levels of intra-islet insulin. 


\section{Methods}

\section{Animals and surgery preparations}

In the dog, the pancreas can be divided into three parts: the dorsal lobe supplied by branches of the splenic artery and vein, the ventral lobe which shares the blood supply of the proximal duodenum, and the embryologically-distinct uncinate process supplied by the inferior pancreatic artery and vein. Although the uncinate process is well known to be glucagon poor, the ventral lobe, studied in these experiments, has a glucagon content similar to the glucagon-rich dorsal lobe $(24,25)$. (This was confirmed by measurements of glucagon content in our laboratory.) In these experiments the circulation to the dorsal lobe was transiently clamped during alloxan injection (see below) to protect its beta cells from destruction. The ventral lobe was exposed to the alloxan and became insulin deficient. Glucagon secretion was studied from the ventral lobe of non-alloxan-injected dogs, alloxan-injected dogs, and alloxan-injected, insulin-infused dogs (see below). The procedure was performed in two stages:

\section{STAGE ONE: PANCREATIC CLAMPING DURING ALLOXAN INJECTION}

Adult, mongrel dogs (weight $22-43 \mathrm{~kg}$ ) were fasted overnight and anesthetized with pentobarbital sodium $(30 \mathrm{mg} / \mathrm{kg}$ i.v. and $0.1-0.2 \mathrm{mg} / \mathrm{kg}$ per min infusion). Preoperatively, the dogs were hydrated by infusing 1.5 liters of $0.9 \%$ saline and given mannitol $(25 \mathrm{~g})$ via a central venous catheter in order to create an osmotic diuresis and thus minimize subsequent alloxan-induced renal damage. A laparotomy was performed and a clamp was placed across the vascular bundle supplying the dorsal lobe of the pancreas. Another clamp was placed between the dorsal and ventral lobes, thus temporarily isolating the dorsal lobe from the systemic circulation. A bolus of alloxan $(65 \mathrm{mg} / \mathrm{kg})$ was then injected into a central vein over a period of $30 \mathrm{~s}$ and the clamps were removed $2 \mathrm{~min}$ later. Because alloxan has a half-life of less than $1 \min (23,26)$, the B cells of the dorsal lobe were expected to be protected from the alloxan. The dorsal lobe rapidly regained normal color after removal of the clamps. The dogs recovered from the laparotomy and 2-3 wk later stage two was performed.

\section{STAGE TWO: CANNULATION OF PANCREATIC VEIN}

In these acute experiments the dogs were anesthetized with pentobarbital sodium $(30 \mathrm{mg} / \mathrm{kg}$ injection and $0.1-0.2 \mathrm{mg} / \mathrm{kg}$ per min infusion) and a laparotomy was performed. The surgical procedure has been previously described (27). Briefly, the superior pancreatico-duodenal vein, which drains the ventral lobe of the pancreas, was cannulated with a silastic catheter and bypassed through an electromagnetic flow probe and a sampling port into the portal vein. The small vascular branches between the duodenum and pancreas were ligated and cut. This allowed the measurement of insulin (I), glucagon (G), and pancreatic somatostatin (SS) output from the ventral pancreatic lobe without contamination by duodenal venous drainage. In addition, the femoral artery was cannulated for blood pressure recording and blood sampling.

In experimental protocol 2 (see below), the superior pancreaticoduodenal artery was also cannulated and infused with either saline or insulin at a rate of $0.2 \mathrm{ml} / \mathrm{min}$.

Experimental protocol I: four step glucose infusion. Secretion of G, I, and SS from the control or insulin-deficient ventral lobe of the pancreas were measured in eight alloxan-treated and seven controls dogs in response to arginine and to four levels of increasing hyperglycemia. Blood samples were drawn simultaneously from the femoral artery and pancreatic vein $-15,-5$, and $0 \mathrm{~min}$. Arginine, $2.5 \mathrm{~g}$, was given by bolus intravenous injection and blood was drawn 2,5,10, and 15 min after the injection. In addition, femoral arterial blood samples were taken at

1. Abbreviations used in this paper: G, glucagon; I, insulin; IRG, immunoreactive glucagon; IRI, immunoreactive insulin; SLI, somatostatinlike immunoreactivity; SS, somatostatin.
$3,4,6$, and $8 \mathrm{~min}$ after the arginine injections. Arginine was administered to six of the eight alloxan-treated animals and all seven of the control animals.

After $45 \mathrm{~min}$, a second set of baseline samples at $-15,-5$, and 0 min were drawn. Glucose was administered by intravenous bolus and constant infusion at four different rates (steps 1-4) (see below). Simultaneous blood samples were obtained from the femoral artery and pancreatic vein at $5,10,20,30$, and 35 min after each bolus.

\begin{tabular}{ccc} 
Protocol I & \\
\hline Step & $\begin{array}{c}\text { Intravenous } \\
\text { glucose bolus }\end{array}$ & $\begin{array}{c}\text { Intravenous } \\
\text { glucose infusion }\end{array}$ \\
\hline & $\mathrm{mg} / \mathrm{kg}$ & $\mathrm{mg} / \mathrm{kg}$ per min $\times 35 \mathrm{~min}$ \\
One & 25 & 2.5 \\
Two & 25 & 5 \\
Three & 50 & 10 \\
Four & 200 & 40 \\
\end{tabular}

Experimental protocol II: intrapancreatic insulin infusion and two step glucose infusion. In a separate set of alloxantreated dogs $(n=6)$, insulin was replaced in the alloxandamaged ventral lobe by infusing exogenous insulin $(500 \mathrm{mU} /$ $\min \times 90 \mathrm{~min}$ ) into the superior pancreatico-duodenal artery. This insulin dose was calculated to reproduce or exceed the intra-islet insulin level at which there was acute suppression of immunoreactive glucagon (IRG) (step 2) seen in control animals during protocol $\mathrm{I}$. The calculation assumed that blood flow to the pancreatic islet is $10 \%$ of the total pancreatic blood flow and that therefore the insulin concentration in the pancreatico-duodenal vein is tenfold lower than that in pure islet blood. We therefore infused insulin at a rate at least 10-fold higher than the insulin output seen in control animals in protocol I, step 2. Additionally, because marked IRG suppression was seen in protocol I control dogs at glucose infusion steps 3 and 4, glucose was infused at these rates during protocol II (see below).

Protocol II

\begin{tabular}{|c|c|c|c|}
\hline & \multirow{2}{*}{$\frac{\text { Pancreatic duodenal }}{\text { Artery infusion }}$} & \multicolumn{2}{|c|}{ Peripheral glucose } \\
\hline & & IV bolus & Infusion \\
\hline & $500 \mathrm{mU} / \mathrm{min}$ & $\mathrm{mg} / \mathrm{kg}$ & $\mathrm{mg} / \mathrm{kg}$ per min \\
\hline Insulin infusion & Insulin & - & - \\
\hline Step three & Insulin & 50 & 10 \\
\hline Step four & Insulin & 200 & 40 \\
\hline
\end{tabular}

\section{Assays}

Blood samples for assay of immunoreactive insulin (IRI) and glucose were drawn on EDTA, those for IRG on benzamidine and heparin (28), and those for somatostatin-like immunoreactivity (SLI) on a mixture of anticoagulants and proteolytic inhibitors as described by De Haen et al. (29). The radioimmunoassays for IRI (30), IRG (27), and SLI (27) have been previously described.

\section{Data analysis}

Pancreatic hormone outputs from the ventral lobe were calculated by subtracting the femoral arterial concentrations from the pancreatic ve- 
nous concentrations and multiplying the difference by the pancreatic venous plasma flow. In each dog, hormone outputs at 10, 20,30, and $35 \mathrm{~min}$ of each step were averaged. IRG and SLI outputs are expressed as mean percentage change from basal $\pm S E$. The ventral lobe hormone responses to arginine were calculated as the area under the curve above baseline from values obtained from samples at 2-15 min.

\section{Statistical analysis}

Analysis of hormone outputs were done using the Dunnett's test for multiple comparisons versus baseline on an analysis of variance with repeated measures. Significance was accepted at the 5\% level throughout. All results are expressed as mean \pm SEM.

\section{Results}

\section{Experimental protocol I: four step glucose infusion}

Responses to arginine. To determine if the alloxan exposure was sufficient to damage the majority of B cells in the ventral lobe of the pancreas, we measured and compared the integrated acute hormone responses with an arginine bolus $(5 \mathrm{~g}$ i.v.) from the ventral lobe of either alloxan-treated $(n=6)$ or control $(n=7)$ dogs. The integrated acute ventral lobe insulin responses to arginine (2-15 min) were markedly impaired in alloxan-treated dogs compared with the control animals $(10.5 \pm 2.4$ vs. $73.2 \pm 15.7 \mathrm{mU} ; P<0.005 ; \overline{\mathrm{x}} \pm$ SEM). In contrast, the integrated acute glucagon response to arginine in control animals $(5.1 \pm 1.3 \mathrm{ng})$ was not different than that in alloxantreated dogs $(4.1 \pm 1.0 \mathrm{ng})$. The integrated acute somatostatin response to arginine appeared to be higher in alloxan-treated as compared with control animals $(8.3 \pm 1.5$ vs. $4.8 \pm 1.1 \mathrm{pmol})$, but the difference was not significant $P=0.07$ ).

Glucose infusion. To determine if the momentary clamping of the dorsal pancreas protected enough B cells to prevent fasting hyperglycemia in the alloxan-treated animals, glucose values were measured in both control and alloxan-treated animals both before and during surgery. Arterial plasma glucose was $104 \pm 8 \mathrm{mg} / \mathrm{dl}($ mean $\pm \mathrm{SE})$ in control animals and $102 \pm 3 \mathrm{mg} / \mathrm{dl}$ in alloxan-treated dogs both before anesthesia $(P=N S)$. Mean glucose after induction of anesthesia and surgery was $112 \pm 2$ $\mathrm{mg} / \mathrm{dl}$ in controls and $125 \pm 9 \mathrm{mg} / \mathrm{dl}$ in alloxan-treated animals.

Glucose was infused at four different rates (steps $1-4$, see Methods) to determine the amount of hyperglycemia necessary to suppress glucagon secretion in both control and alloxantreated animals. Mean $( \pm \mathrm{SE})$ plasma glucose in control dogs at step one was $123 \pm 2 \mathrm{mg} / \mathrm{dl}$; step two, $153 \pm 6 \mathrm{mg} / \mathrm{dl}$; step three, $212 \pm 14 \mathrm{mg} / \mathrm{dl}$; and step four, $468 \pm 45 \mathrm{mg} / \mathrm{dl}$ (Fig. 1). In alloxan-treated dogs the mean plasma glucose were significantly higher $(P \leq 0.01)$ than in control dogs at each step. At step one, glucose in the alloxan-treated dogs was $146 \pm 10 \mathrm{mg} / \mathrm{dl}$; step two, $185 \pm 12 \mathrm{mg} / \mathrm{dl}$; step three, $273 \pm 13 \mathrm{mg} / \mathrm{dl}$; and step four, $594 \pm 51 \mathrm{mg} / \mathrm{dl}$ (Fig. 1).

Insulin responses. To determine the magnitude of the ventral B cell response to the four steps of glucose in both control and in the alloxan-treated animals, we measured IRI output from the ventral lobe of the pancreas in both groups (see Fig. 2). In control dogs, the mean basal IRI output from the ventral lobe was $6.7 \pm 1.9 \mathrm{mU} / \mathrm{min}$. At step one IRI output rose to a steady level of $11.6 \pm 2.7 \mathrm{mU} / \mathrm{min}$; step two, $25.7 \pm 6.1 \mathrm{mU} /$ $\mathrm{min}$; step three, $54.2 \pm 12 \mathrm{mU} / \mathrm{min}$; and step four, 77.5 \pm 25.9 $\mathrm{mU} / \mathrm{min}$. In contrast, in alloxan-treated dogs the mean basal IRI output from the ventral lobe was $2.7 \pm 0.6 \mathrm{mU} / \mathrm{min}$, rose to $4.5 \pm 1$ at step one, and then stabilized at $5.6 \pm 1.4,5.6 \pm 1.2$, and $5.2 \pm 1 \mathrm{mU} / \mathrm{min}$ at steps two through four. Thus, the IRI outputs were significantly $(P \leq 0.002)$ and markedly lower in the alloxan-treated dogs both before and during the glucose infusions.

Glucagon response. To determine which step of glucose infusion was sufficient to suppress glucagon secretion we measured ventral lobe IRG output before and during the four steps of glucose infusions (see Fig. 3). In control dogs, the mean basal IRG output from the ventral lobe was $1.24 \pm 0.36 \mathrm{ng} / \mathrm{min}$. At step one there was no significant change in IRG output $(-6 \pm 9 \%)$ but output decreased significantly to $-49 \pm 4,-50 \pm 8$, and $-62 \pm 6 \%$ of basal at steps two, three, and four, respectively (all $P<0.001$ ). In alloxan-treated dogs, the basal IRG output was $1.20 \pm 0.32 \mathrm{ng} / \mathrm{min}$. In contrast to the control dogs, there was no significant change from baseline IRG at steps one through four, although there appeared to be a small progressive trend downward $(+14 \pm 15,-3 \pm 19,-24 \pm 15$, and $-29 \pm 16 \%)$ $(P=\mathrm{NS})$. Thus, the control dogs had an abrupt suppression of glucagon at step 2 (glucose, $153 \pm 6 \mathrm{mg} / \mathrm{dl}$ ) followed by a small further decline in glucagon secretion. In the alloxan-treated dogs this abrupt suppression was absent; however, there was a slow downward trend of glucagon secretion with increasing glucose levels that did not achieve statistical significance.

Somatostatin response. To determine if the suppression of glucagon secretion in control dogs was indirectly due to stimulation of pancreatic somatostatin secretion by hyperglycemia, we measured ventral lobe SLI output during the four glucose steps (see Fig. 4). In control dogs, the mean basal SLI output from the ventral lobe was $2.4 \pm 0.8 \mathrm{pmol} / \mathrm{min}$. SLI output did not rise significantly above baseline at step one $(0 \pm 8 \%)$, step two $(6 \pm 9 \%)$, or step three $(39 \pm 12 \%)$ despite the significant suppression of glucagon secretion at step 2. At step four SLI output rose significantly $(+87 \pm 28 \%)(P<0.01)$. In the alloxan-treated animals, the basal SLI output was $2.6 \pm 0.4 \mathrm{pmol} / \mathrm{min}$, not different from control animals. However, no significant change in

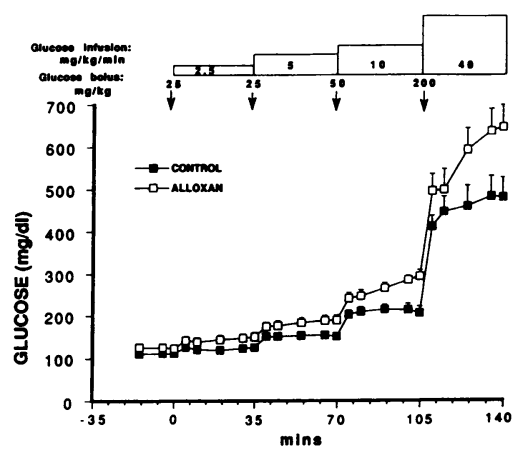

Figure 1. Protocol I: systemic glucose concentrations. Arterial plasma glucose concentrations $(\mathrm{mg} / \mathrm{dl})$ before and during a four-step intravenous glucose infusion in control $(n=7)$ and alloxan-treated $(n$ $=8)$ anesthetized dogs (mean $\pm \mathrm{SE}$ ).

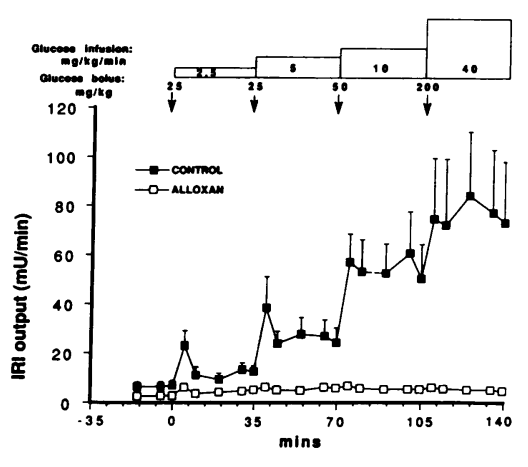

Figure 2. Protocol I: insulin output. IRI output from the ventral lobe of the in situ dogs pancreas before and during a four-step intravenous glucose infusion in control $(n=7)$ and alloxan-treated $(n=8)$ anesthetized dogs (mean \pm SE). 


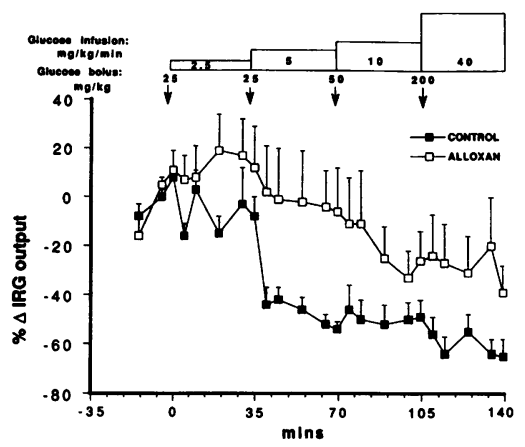

Figure 3. Protocol I: glucagon output. IRG output from the ventral lobe of the in situ dog pancreas expressed as percent change from baseline before and during a four-step intravenous glucose infusion in control $(n=7)$ and alloxan-treated $(n=8)$ anesthetized dogs $($ mean \pm SE).
SLI output occurred in response to hyperglycemia: step one, $+11 \pm 6 \%$; step two, $-3 \pm 11 \%$; step three, $-10 \pm 7 \%$; and step four, $=+6 \pm 13 \%$.

Experimental protocol II: intrapancreatic insulin infusion with a two step glucose infusion in alloxan-treated dogs

To determine the importance of islet insulin per se in the response of the A cells to hyperglycemia, we infused high concentrations of insulin into the pancreatic artery supplying the alloxan-treated ventral lobe of the pancreas and then infused glucose intravenously at the two highest rates of the previous protocol (steps three and four).

Glucose values. Basal values after induction of anesthesia and surgery were $116 \pm 4.5 \mathrm{mg} / \mathrm{dl}$. Mean $( \pm \mathrm{SE})$ plasma glucose during insulin infusion alone was $112 \pm 2.5 \mathrm{mg} / \mathrm{dl}$, plasma glucose at step three was $185 \pm 19.4 \mathrm{mg} / \mathrm{dl}$, and step four was $430 \pm 41.8 \mathrm{mg} / \mathrm{dl}$ (see Fig. 5).

Insulin responses. During the first 25 min of intra-pancreatic insulin infusion, calculated IRI output rose to $439 \pm 126$ $\mathrm{mU} / \mathrm{min}$, more than 10-fold higher than the endogenous insulin output seen in control animals in protocol I, step 2 (see Methods). Calculated IRI output during both steps of glucose infusion, step three $(553 \pm 92 \mathrm{mU} / \mathrm{min})$ and step four $(599 \pm 111$ $\mathrm{mU} / \mathrm{min}$ ), was not significantly different than during infusion of insulin alone.

Glucagon responses. In these alloxan-treated dogs the basal IRG output was $1.5 \pm 0.45 \mathrm{ng} / \mathrm{min}$. In response to intrapancreatic insulin infusion alone, IRG output did not change signifcantly $(+4 \pm 15 \%$ from baseline). However, IRG output decreased significantly when glucose was infused intravenously during intrapancreatic insulin infusion. IRG output decreased

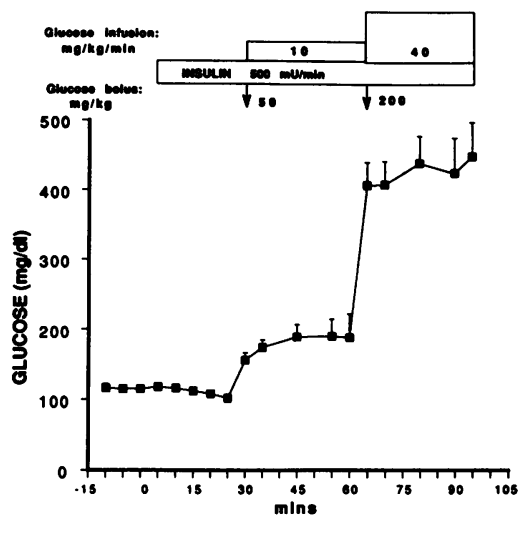

Figure 5. Protocol II: systemic glucose concentration. Arterial plasma glucose concentration $(\mathrm{mg} / \mathrm{dl})$ before and during infusion of intrapancreatic insulin alone and in conjunction with a two-step intravenous glucose infusion in alloxan-treated $(n=6)$ anesthetized dogs (mean \pm SE).

by $-42 \pm 10 \%(P<0.05)$ from baseline during glucose step three and by $-68 \pm 5 \%(P<0.01)$ from baseline during glucose step four (see Fig. 6).

Somatostatin responses. To determine if restored glucagon suppression by hyperglycemia coincided with restoration of the pancreatic somatostatin response to hyperglycemia, ventral lobe SLI output was measured. In these alloxan-treated dogs, the basal SLI output was $1.4 \pm 0.3 \mathrm{pmol} / \mathrm{min}$. There was no significant increase in SLI output after infusion of insulin alone $(+16 \pm 22 \%)$ or after the step 3 glucose infusion $(+32 \pm 29 \%)$. There was, however, a significant increase of ventral lobe SLI output during step 4 glucose infusion $(+102 \pm 46 \%)(P<0.05)$ (Fig. 7).

\section{Discussion}

This study was designed to determine the mechanism of the insensitivity of the islet A cell to the suppressive effects of hyperglycemia in insulin-deficient animals. Specifically, we sought to determine if local insulin deficiency, in the absence of chronic hyperglycemia, could produce such insensitivity. Further, we sought to determine whether the presumably large and rapid increases of local insulin that normally accompany acute hyperglycemia in noninsulin-deficient animals suppress the A cell directly, or whether high local levels of insulin simply allow glucose to suppress the A cell. Finally, we also carefully evaluated the potential role of pancreatic somatostatin in such glucagon suppression by examining the dose-response relation between glucose-induced stimulation of pancreatic secretion and glucose-induced suppression of pancreatic glucagon secretion

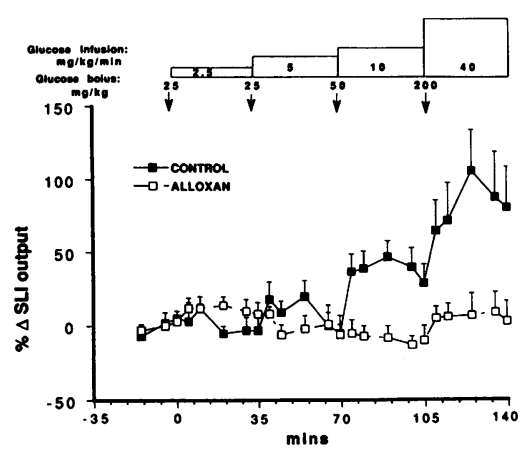

Figure 4. Protocol I: pancreatic somatostatin output. SLI output from the ventral lobe of the in situ dog pancreas expressed as percentage change from baseline before and during a four-step intravenous glucose infusion in control $(n=7)$ and alloxan-treated $(n=8)$ anesthetized dogs (mean \pm SE).

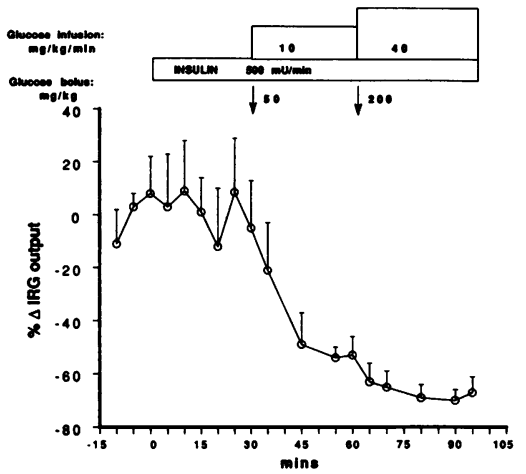

Figure 6. Protocol II: glucagon output. IRG output from the ventral lobe of the in situ dog pancreas expressed as percentage change from baseline before and during infusion of intrapancreatic insulin alone and in conjunction with a two-step intravenous glucose infusion in alloxan-treated $(n=6)$ anesthetized dogs (mean $\pm \mathrm{SE}$ ). 


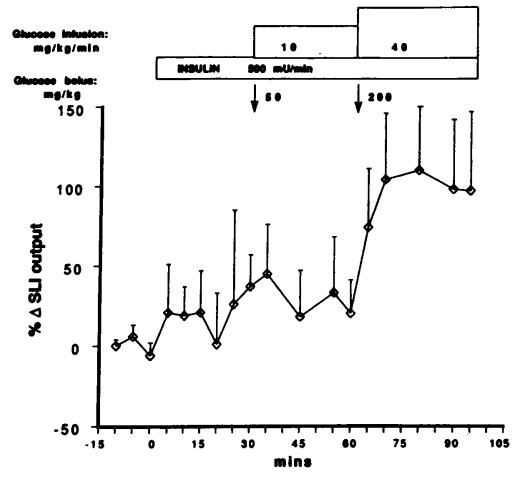

Figure 7. Protocol II: somatostatin output. SLI output from the ventral lobe of the in situ dog pancreas expressed as percentage change from baseline before and during infusion of intrapancreatic insulin alone and in conjunction with a twostep intravenous glucose infusion in alloxan-treated $(n=6)$ anesthetized dogs (mean \pm SE).

in noninsulin-deficient animals, and by examining the effect of local insulin deficiency and local insulin repletion on the pancreatic somatostatin response to acute hyperglycemia.

Because severe insulin deficiency usually causes marked fasting hyperglycemia in either animals or man, chronic hyperglycemia itself has long been considered a candidate to mediate the glucose insensitivity of the A cell seen in diabetes. Chronic hyperglycemia has been shown to alter islet cell responses (1622). Creation of mild to moderate chronic hyperglycemia after partial pancreatectomy or streptozocin treatment in rats results in impaired insulin responses to acute glucose infusions as well as impaired glucose regulation of nonglucose secretagogues $(16,18)$. Alleviation of the chronic hyperglycemia by insulin treatment or phloridzin prevents these B cell secretory defects $(19,20)$. Additionally, mild chronic hyperglycemia alters the A cell response to acute hypoglycemia (31). Thus, it is likely that the chronic hyperglycemia of diabetes contributes to the insensitivity of the A cell. However, the question addressed in this study concerns the role of local insulin deficiency per se. To answer that question it was necessary to avoid the complication of chronic hyperglycemia while still producing insulin deficiency.

In this study local insulin deficiency was produced in the ventral portion of the canine pancreas by using a modification of the technique of Gomori and Goldner (23). This approach takes advantage of the very short half-life of alloxan in blood $(23,26)$. By briefly clamping the vascular supply to the dorsal lobe of the pancreas for $2 \mathrm{~min}$, we were able to isolate it from the B cell toxic effects of systemically injected alloxan and at the same time destroy the B cells in the unprotected ventral lobe. Sufficient B cells were protected in the dorsal lobe to maintain fasting normoglycemia, though under conditions of anesthesia and surgical stress, plasma glucose levels in the alloxan treated dogs were slightly higher than controls. In contrast, severe B cell destruction occurred in the ventral lobe as evidenced by markedly diminished ventral lobe insulin output in response to both arginine and glucose. Thus, the model apparently fulfilled the dual goals of local insulin deficiency without the chronic severe hyperglycemia usually associated with this degree of insulin deficiency.

The data from protocol I demonstrate that local intra-islet insulin deficiency is associated with impaired glucagon suppression by acute hyperglycemia. For example, in the control dogs there was a marked suppression of glucagon secretion when glucose rose to $\sim 150 \mathrm{mg} / \mathrm{dl}$, which was absent in the alloxan-treated dogs, although in the later condition glucagon output appears to decline slowly with progressive hyperglycemia. Thus, at marked hyperglycemia an insulin-independent process could be responsible for some glucagon suppression as suggested by previous work with isolated A cells (5). However, we conclude that at moderate hyperglycemia, local insulin deficiency alone produces an insensitivity of the A cell to glucose.

Others have used different techniques to circumvent the complication of chronic hyperglycemia that usually accompanies severe insulin deficiency. Starke et al. reversed chronic hyperglycemia by lowering the blood glucose levels of alloxan diabetic dogs by the administration of phloridzin, a drug that causes renal glycosuria (2). In contrast to our findings, infusion of glucose alone to increase plasma levels from 65 to $350 \mathrm{mg} / \mathrm{dl}$ resulted in a suppression of glucagon secretion $\sim 50 \%$ of baseline which was equivalent to controls. However, in that study, the glucose was raised from hypoglycemic, not euglycemic levels. This difference is important because the mechanism by which hypoglycemia stimulates glucagon secretion is likely to be different from that by which hyperglycemia suppresses it $(32,33)$. For example, the activation of the autonomic nerves of the pancreas is negligible at euglycemia $(34,35)$ but probably plays a role during hypoglycemia.

It is unlikely that the insensitivity of the pancreatic A and D cells to hyperglycemia in alloxan-treated animals is due to direct effect of the drug because alloxan itself is thought to have no major direct toxic effects on either the A or D cells $(26,36)$. The data in this study support that view because the basal and arginine-stimulated glucagon and somatostatin outputs in the alloxan-treated animals were not lower than those from control animals. Additionally, repleting insulin to the pancreas restored the ability of the alloxan-exposed A and D cells to respond normally to acute hyperglycemia.

Alternatively, local insulin deficiency could have prevented the rise of somatostatin and by this mechanism prevent suppression of glucagon secretion. However, in the control animals the acute suppression of glucagon occurred at step two (glucose levels $\sim 150 \mathrm{mg} / \mathrm{dl}$ ) and significant stimulation of somatostatin secretion occurred only by step 4 (glucose levels $>400 \mathrm{mg} / \mathrm{dl}$ ). Thus, increased somatostatin secretion is probably not the cause of this particular suppression of glucagon secretion. This observation is in complete agreement with earlier dose-response studies of Sorensen and Elde performed in the isolated rat pancreas (4). It may, however, appear to be in conflict with previous work from our laboratory $(12,27)$. We had found that both at euglycemia and marked hyperglycemia, suppression of somatostatin led to stimulation of IRG secretion. Thus SS secretion may tonically restrain pancreatic glucagon secretion, but the suppression of glucagon secretion, which occurs during moderate hyperglycemia in the dog, is not mediated by increased somatostatin secretion per se.

Finally, the insensitivity of the A cell could be due to the loss of a suppressive effect of local insulin directly on the A cell, or the loss of a permissive effect of insulin on the ability of glucose to directly suppress the A cell. To distinguish between these two possible mechanisms we infused insulin at high rates both before and during hyperglycemia directly into the pancreatic artery that supplies the ventral lobe (experimental protocol II). The insulin dose was calculated (see Methods) to create levels of intra-islet insulin at least equivalent to those that occurred during hyperglycemia in control dogs in protocol I. We wished to determine if high levels of intra-islet insulin, with or 
without hyperglycemia, suppressed glucagon secretion and whether somatostatin responses were restored.

In these studies, local insulin infusion into the B cell-deficient lobe did not, by itself, cause any change in IRG secretion, suggesting that high levels of intra-islet insulin do not directly mediate suppression of the A cell. This finding contrasts with two previous studies. In one study, Starke (3) noted a fall in IRG with a peripheral infusion of insulin at normoglycemia; however, this fall in IRG could have been due to insulin's suppressive effect on endogenous glucagon secretagogues such as plasma amino acids. Secondly, Maruyama (11) observed an increase in IRG secretion with acute immuneoneutrilization of intra-islet insulin in the isolated perfused pancreas. These results are harder to reconcile with our data. One possibility is that the chronic local insulin deficiency in our model renders the A cells insensitive to the direct suppressive effect of the short term insulin infusion. If so, then a time-dependent direct effect of insulin may have contributed to the late suppression of glucagon secretion during hyperglycemia.

When hyperglycemia was induced during the intra-islet insulin repletion, IRG secretion was suppressed, just as in control animals. We therefore conclude that high intra-islet levels of insulin allow glucose to directly suppress glucagon secretion in response to acute hyperglycemia. Studies of other workers have suggested that insulin is necessary for the suppression of glucagon by glucose. In high concentrations, insulin has been reported to inhibit glucagon secretion both in vivo and in vitro (9-11, 37, 38). Retrograde perfusion studies designed to prevent the exposure of the A cell to high levels of intra-islet insulin also prevented IRG suppression with hyperglycemia (6), and neutralization of insulin by a high affinity anti-insulin antiserum stimulated glucagon release in both the isolated rat (39) and dog pancreas (40). The demonstration that blood flow is from the central B cell core of the islet to the D and A cells in the mantle of the islet (15) suggests that the A and D cells are usually exposed to very high levels of insulin. In contrast, the data of this study suggest that these high levels of insulin are, by themselves, not sufficient to inhibit glucagon secretion, but are needed to maintain the glucose sensitivity of the A cells.

These data also demonstrate that the pancreatic somatostatin response to hyperglycemia is lost during chronic local insulin deficiency. This finding is in agreement with those of Hermansen (41) and Trimble (42) who found that acute hyperglycemia did not stimulate somatostatin secretion in either the diabetic dog pancreas (41) or diabetic rat islets (42), respectively. It is unlikely that the insensitivity of the $D$ cell is due to a lack of direct effect of insulin on the D cell, as our data, and those of others (41-44), suggest that exogenous insulin at normoglycemia does not stimulate somatostatin secretion. Nevertheless, it remains possible that a stimulatory effect of insulin on the D cell may have occurred in our study after a longer period of insulin infusion.

This study did demonstrate that intra-islet insulin restored the stimulation of somatostatin secretion by acute hyperglycemia, suggesting that the normal somatostatin response to acute hyperglycemia requires the presence of high levels of intra-islet insulin. This finding contrasts with that of Hermansen who found that the addition of insulin to the diabetic pancreas failed to reverse the deficit in somatostatin secretion (41). However, we replaced insulin to achieve pancreatic vein insulin concentrations 10- to 20-fold higher than those of Hermansen. Further, the $3 \mathrm{~d}$ of diabetic hyperglycemia present in Herman- sen's study may have been sufficient to render the D cell insensitive to acute hyperglycemia (41). This interpretation is supported by the study of Trimble et al., in which insulin treatment of chronically diabetic rats restored the ability of the islets to respond to acute hyperglycemia in vitro (42). However, the normalized somatostatin response seen in Trimble's study occurred in insulin-deficient rat islets (42), and thus appears to be in direct contrast to our finding that high rates of insulin infusion are needed to restore the D cell's secretory response to glucose. The reason for this discrepancy remains unclear.

In conclusion, this study was designed to determine the mechanism of the insensitivity of the islet A cell to the suppressive effects of hyperglycemia in insulin-deficient animals. We have shown that in the presence of local insulin deficiency and the absence of chronic hyperglycemia, the A cell insensitivity to glucose remains. Additionally, although pancreatic somatostatin at euglycemia and marked hyperglycemia can tonically inhibit glucagon secretion, this study demonstrates that somatostatin does not mediate the acute fall in IRG secretion that occurs at moderate hyperglycemia. Finally, this study demonstrates that the large local insulin response to acute hyperglycemia in healthy animals does not directly suppress the A cell or stimulate the D cell, but simply allows glucose to do so.

\section{Acknowledgments}

We thank Hong Ngugen, Ruth Hollingsworth, and Rix Kuester for their technical assistance and Lynn Spivey for word processing. In addition, we thank Dr. J. P. Palmer, and Dr. D. Porte, Jr., for helpful discussions of the data.

These studies were supported by: Juvenile Diabetes Foundation grant 184117 (to Dr. Klaff); Veterans Administration Merit Review, National Institutes of Health grants DK-12829 and DK-17047 (to Dr. Taborsky); American Diabetes Association Washington Affiliate Fellowship Grant Award, NIH grant DK-08211 (to Dr. Greenbaum).

\section{References}

1. Chen, L., I. Komiya, L. Inman, K. McCorkle, T. Alam, and R. H. Unger. 1989. Molecular and cellular responses of islets during perturbations of glucose homeostasis determined by in situ hybridization histochemistry. Proc. Natl. Acad. Sci. USA. 86:1367-1371.

2. Starke, A., S. Grundy, J. D. McGarry, and R. H. Unger. 1985. Correction of hyperglycemia with phloridzin restores the glucagon response to glucose in insulin-deficient dogs: implications for human diabetes. Proc. Natl. Acad. Sci. USA. 82:1544-1546.

3. Starke, A., T. Imamura, and R. H. Unger. 1987. Relationship of glucagon suppression by insulin and somatostatin to the ambient glucose concentration. $J$. Clin. Invest. 79:20-24.

4. Sorenson, R. L., and D. P. Elde. 1983. Dissociation of glucose stimulation of somatostatin and insulin release from glucose inhibition of glucagon release in the isolated perfused rat pancreas. Diabetes. 32:561-567.

5. Pipeleers, D. G., F. C. Schuit, C. F. H. Van Schravendijk, and M. Van De Winkel. 1985. Interplay of nutrients and hormones in the regulation of glucagon release. Endocrinology. 117:817-823.

6. Stagner, J. I., and E. Samols. 1986. Retrograde perfusion as a model for testing the relative effects of glucose versus insulin on the A cell. J. Clin. Invest. 77:1034-1037.

7. Muller, W. A., G. R. Faloona, and R. H. Unger. 1971. The effect of experimental insulin deficiency on glucagon secretion. J. Clin. Invest. 50:1992-1999.

8. Braaten, J. T. G. R. Faloona, and R. H. Unger. 1974. The effect of insulin on the alpha-cell response to hyperglycemia in long standing alloxan diabetes. $J$. Clin. Invest. 53:1017-1021.

9. Buchanan, K. D., and W. A. A. Mawhinney. 1973. Insulin control of glucagon release from insulin-deficient rat islets. Diabetes. 22:801-803.

10. Buchanan, K. D., and W. A. A. Mawhinney. 1973. Glucagon release from isolated pancreas in streptozotocin-treated rats. Diabetes. 22:797-800.

11. Maruyama, H., A. Hisatomi, L. Orci, G. M. Grodsky, and R. H. Unger. 1984. Insulin within islets is a physiologic glucagon release inhibitor. J. Clin. Invest. 74:2296-2299. 
12. Klaff, L. J., and G. J. Taborsky, Jr. 1987. Pancreatic somatostatin is a mediator of glucagon inhibition by hyperglycemia. Diabetes. 36:592-596.

13. Filipponi, P., F. Gregorio, S. Cristallini, C. Ferrandina, I. Nicoletti, and F. Santeusanio. 1986. Selective impairment of pancreatic A cell suppression by glucose during acute alloxan-induced insulinopenia: in vitro study on isolated perfused rat pancreas. Endocrinology. 119:408-415.

14. Kaestner, K. H., R. J. Christy, J. C. McLenithan, C. T. Braiterman, P. Cornelius, P. H. Pekala, and M. D. Lane. 1989. Sequence, tissue distribution and differential expression of MRNA for a putative insulin-response glucose transporter in mouse 3T3-L1 adipocytes. Proc. Natl. Acad. Sci. USA. 86:3150-3154.

15. Bonner-Weir, S., and L. Orci. 1982. New perspectives on the microvasculature of the islets of Langerhans in the rat. Diabetes. 31:883-889.

16. Leahy, J. L., S. Bonner-Weir, and G. C. Weir. 1984. Abnormal glucose regulation of insulin secretion in models of reduced B-cell mass. Diabetes. 33:667-673.

17. Unger, R. H. 1985. Glucagon physiology and pathophysiology in the light of new advances. Diabetologia. 28:574-578.

18. Unger, R. H., and S. Grundy. 1985. Hyperglycaemia as an inducer as well as a consequence of impaired islet cell function and insulin resistance: implications for the management of diabetes. Diabetologia. 28:119-121.

19. Rossetti, L., G. I. Shulman, W. Zawalich, and R. A. DeFronzo. 1987. Effect of chronic hyperglycemia on in vivo insulin secretion in partially pancreatectomized rats. J. Clin. Invest. 80:1037-1044.

20. Leahy, J. L., S. Bonner-Weir, and G. C. Weir. 1985. Abnormal insulin secretion in a streptozocin model of diabetes. Diabetes. 34:660-666.

21. Leahy, J. L., S. Bonner-Weir, and G. C. Weir. 1988. Minimal chronic hyperglycemia is a critical determinant of impaired insulin secretion after an incomplete pancreatectomy. J. Clin. Invest. 81:1407-1414.

22. Imamura, T., M. Koffler, J. H. Helderman, D. Prince, R. Thirlby, L. Inman, and R. H. Unger. 1988. Severe diabetes induced in subtotally depancreatized dogs by sustained hyperglycemia. Diabetes. 37:600-609.

23. Gomori, G., and M. G. Goldner. 1945. Acute nature of alloxan damage. Proc. Soc. Exp. Biol. Med. 58:232-233.

24. Gingerich, R. L., P. E. Lacy, R. E. Chance, and M. G. Johnson. 1978 Regional pancreatic concentration and in vitro secretion of canine pancreatic polypeptide insulin and glucagon. Diabetes. 27:96-101.

25. Gersell, D. J., R. L. Gingerich, and M. H. Greider. 1979. Regional distribution and concentration of pancreatic polypeptide in the human and canine pancreas. Diabetes. 28:11-15.

26. Rerup, C. C. 1970 . Drugs producing diabetes through damage of the insulin secreting cells. Pharmacol. Rev. 22:485-518.

27. Taborsky, G. J., Jr. 1983. Evidence of a paracrine role for pancreatic somatostatin in vivo. Am. J. Physiol. 245:E598-E603.

28. Ensinck, J. W., C. Shepard, R. J. Dudl, and R. H. Williams. 1972. Use of benzamidine as a proteolytic inhibitor in the radioimmunoassay of glucagon in plasma. J. Clin. Endocrinol. Metab. 35:463-467.

29. De Haen, C., S. A. Little, J. M. May, and R. H. Williams: 1978. Characterization of proinsulin-insulin intermediates in human plasma. J. Clin. Invest 62:727-737.

30. Morgan, C. R., and A. Lazarow. 1963. Immunoassay of insulin: two antibody system. Plasma insulin levels of normal, subdiabetic and diabetic rats. Diabetes. 12:115-126.

31. Wier, G. C., S. D. Knowlton, and D. B. Martin. 1974. Glucagon secretion from the perfused rat pancreas. J. Clin. Invest. 54:1403-1412.

32. Bolli, G., P. De Feo, G. Perriello, S. De Cosmo, P. Compagnucci, F. Santeusanio, P. Brunetti, and R. H. Unger. 1984. Mechanisms of glucagon secretion during insulin-induced hypoglycemia in man: role of the beta cell and arterial hyperinsulinemia. J. Clin. Invest. 73:917-922.

33. Samols, E., S. Bonner-Weir, and G. C. Weir. 1986. Intra-islet insulin-glucagon-somatostatin relationships. Clin. Endocrinol. Metab. 15:33-59.

34. Havel, P. J., R. C. Veith, B. E. Dunning, and G. J. Taborsky, Jr. 1988 Pancreatic noradrenergic nerves are activated by neuroglucopenia but not by hypotension or hypoxia in the dog. J. Clin. Invest. 82:1538-1545.

35. Hisatomi, A., H. Maruyama, L. Orci, M. Vasko, and R. H. Unger. 1985. Adrenergically mediated intrapancreatic control of the glucagon response to glucopenia in the isolated rat pancreas. J. Clin. Invest. 75:420-426.

36. Lenzen, S., and U. Panten. 1988. Alloxan: history and mechanism of action. Diabetologia. 31:337-342.

37. Fujimoto, W. Y., and J. W. Ensinck. 1981. Regulation of A- and B-cell function by insulin and glucagon. Horm. Metab. Res. 13:547-550.

38. Samols, E., J. Tyler, and V. Marks. 1972. Glucagon-insulin interrelationships. In Glucagon, Molecular Physiology, Clinical and Therapeutic Implications. P. J. Lefebvre and R. H. Unger, editors. Pergamon Press Inc., Elmsford, NY. 151-174.

39. Samols, E., J. I. Stagner, R. B. L. Ewart, and V. Marks. 1988. The order of islet microvascular cellular perfusion is $B \rightarrow A \rightarrow D$ in the perfused rat pancreas. J. Clin. Invest. 82:350-353.

40. Stagner, J. I., E. Samols, and S. Bonner-Weir. 1988. B $\rightarrow$ A $\rightarrow$ D pancreatic islet cellular perfusion in dogs. Diabetes. 37:1715-1721.

41. Hermansen, K., H. Orskov, and S. E. Christensen. 1979. Streptozotocin diabetes: a glucoreceptor dysfunction affecting $\mathrm{D}$ cells as well as B and A cells. Diabetologia. 17:385-389.

42. Trimble, E. R., P. P. G. Gerber, and A. E. Renold. 1981. Abnormalities of pancreatic somatostatin secretion corrected by in vivo insulin treatment of streptozotocin-diabetic rats. Diabetes. 30:865-867.

43. Weir, G. C., E. Samols, S. Loo, Y. C. Patel, and K. H. Gabbay. 1979. Somatostatin and pancreatic polypeptide secretion. Diabetes. 28:35-40.

44. Patel, Y. C., M. Amherdt, and L. Orci. 1979. Somatostatin secretion from monolayer cultures of neonatal rat pancreas. Endocrinology. 104:676-679. 